\title{
Modeling Control Strategies and Range Impacts for Electric Vehicle Integrated Thermal Management Systems with MATLAB/Simulink
}

\section{Gene Titov and Jason Aaron Lustbader}

National Renewable Energy Laboratory

CITATION: Titov, G. and Lustbader, J., "Modeling Control Strategies and Range Impacts for Electric Vehicle Integrated Thermal Management Systems with MATLAB/Simulink," SAE Technical Paper 2017-01-0191, 2017, doi:10.4271/2017-01-0191.

Copyright (C) 2017 SAE International

\begin{abstract}
The National Renewable Energy Laboratory's (NREL's) CoolSim MATLAB/Simulink modeling framework was used to explore control strategies for an electric vehicle combined loop system. Three system variants of increased complexity and efficiency were explored: a glycol-based positive temperature coefficient heater (PTC), PTC with power electronics and electric motor (PEEM) waste heat recovery, and PTC with PEEM waste heat recovery plus heat pump versions. Additionally, the benefit of electric motor preheating was considered. A two-level control strategy was developed where the mode selection and component control were treated separately. Only the parameters typically available by vehicle sensors were used to control the system. The control approach included a mode selection algorithm and controllers for the compressor speed, cabin blower flow rate, coolant flow rate, and the front-end heat exchanger coolant bypass rate. The electric motor was bypassed by the cooling circuit until its temperature exceeded the coolant inlet temperature. The impact of these thermal systems on electric vehicle range during warmup was simulated for the Urban Dynamometer Driving Schedule (UDDS) and Highway Fuel Economy Test (HWFET2X) drive cycles weighted $45 \% / 55 \%$ respectively. A range of ambient temperatures from $-20^{\circ} \mathrm{C}$ to $+20^{\circ} \mathrm{C}$ was considered. NREL's Future Automotive Systems Technology Simulator (FASTSim) vehicle modeling tool showed up to a $10.9 \%$ improvement in range for the full system over the baseline during warmup from cold soak. The full system with preheat showed up to $17 \%$ improvement in range.
\end{abstract}

\section{Introduction}

Thermal management systems are important for effective and efficient advanced light- and heavy-duty vehicle design. Developing flexible and cost-effective tools to understand vehicle thermal trade-offs at the system level is critical to designing advanced electrified traction drive systems and their associated thermal controls. When operating, the air-conditioning $(\mathrm{A} / \mathrm{C})$ system is the largest auxiliary energy consumer in a conventional vehicle. $\mathrm{A} / \mathrm{C}$ loads account for more than $5 \%$ of the fuel used annually by light-duty vehicles in the United States [1]. Climate control loads can have an even larger impact on hybrid electric vehicle (EV), plug-in hybrid EV, and all-electric vehicle performance. Hybrid EVs show a $22 \%$ lower fuel economy with the A/C on [2]. For all-electric vehicles, the effect of the climate control system usage is even more severe. Due to a shortage of waste heat, heating of the passenger cabin in EVs has to rely on battery energy. Cooling the cabin can also take a high portion of the energy available in the battery, significantly reducing vehicle efficiency and range. Mitsubishi reports that the range of the $\mathrm{i}-\mathrm{MiEV}$ can be reduced by as much as $68 \%$ when heating and $46 \%$ when cooling the cabin over Japan's $10-15$ cycle [ $\underline{3}]$. The Advanced Powertrain Research Facility at Argonne National Laboratory has reported $59.3 \%$ and $53.7 \%$ reductions in range due to maximum heating and maximum cooling, respectively, for the Ford Focus EV operating on the Urban Dynamometer Driving Schedule (UDDS) cycle [4]. In addition to these climate control impacts, electric-drive vehicles may have additional cooling requirements for the electric traction drive system components, including batteries, power electronics (PE), and electric machines (EM).

To address these challenges, more efficient heating and cooling systems are needed for EVs. These systems often involve running the vapor compression system in heat pump mode to reduce the electrical heating power requirements of the cabin. In some advanced concepts, the traditional liquid-coolant-based thermal management system is supplemented with a refrigerant-based cooling system, which can make the thermal management significantly more complex.

When developing a thermal management system for an internal combustion engine vehicle, it has traditionally been sufficient to simulate the $\mathrm{A} / \mathrm{C}$ system and liquid-coolant-based cooling system separately. For advanced vehicles, especially for hybrid and allelectric vehicles, the benefits of interconnectedness of the thermal management and $\mathrm{A} / \mathrm{C}$ systems can outweigh the associated complexity. This requirement motivates the development of a more integrated simulation approach. 
More complex advanced thermal management systems allow for various alternative modes of operation that can be selected based on driving and ambient conditions. Investigating a number of system alternatives and determining the best ranges for various operating modes with experimental methods can be very time consuming. A good system simulation tool can greatly reduce the time and expense of developing these complex systems.

Thermal system modeling tools should also be able to efficiently co-simulate with vehicle simulation programs and should be applicable for evaluating various control algorithms. The MATLAB/ Simulink simulation environment is popular in the automotive industry and is well suited for developing such models while meeting the requirements of dynamic modeling of complex systems.

To meet the needs of advanced vehicle thermal system simulations, the National Renewable Energy Laboratory (NREL) is building an integrated single- and two-phase thermal system modeling framework in MATLAB/Simulink called CoolSim. This integrated approach allows for rapid system analysis and design in a flexible and open modeling environment. Simulink is a common engineering platform that allows for co-simulation with vehicle models such as Autonomie [5] or in conjunction with NREL's Future Automotive Systems Technology Simulator (FASTSim) [] .

NREL previously developed an A/C system simulation modeling framework in MATLAB/Simulink and validated its results against test bench data. To match the wide range of $\mathrm{A} / \mathrm{C}$ modeling needs, NREL developed models with three different levels of detail: Fully Detailed, Quasi-Transient, and Mapped-Component.

The three models involve different levels of trade-offs between speed and accuracy to meet a wide range of modeling needs. The Fully Detailed model captures the system transient behavior accurately, but it runs at 1/10 of real-time speed [7]. The Quasi-Transient and Mapped-Component models are progressively more simplified while trying to maintain accuracy. These models run at real time and 10 times real-time speed, respectively [ $\underline{8}]$. The goal of these model versions is to provide faster simulation tools for less detailed, vehiclefocused, drive-cycle-based evaluations of A/C systems. For steadystate conditions, the Quasi-Transient model provides essentially the same accuracy as the Fully Detailed model.

The Mapped-Component model does lose some accuracy in steadystate conditions. For the SC03 drive cycle, the averaged results of power and heat exchange rates obtained with the Quasi-Transient model are within $3 \%$ of the Fully Detailed model results. The Mapped-Component model results are within 15\% of the Fully Detailed model results. For both simplified models, short transients, such as those occurring during compressor cycling, produce the most deviation from the Fully Detailed model. Conversion from the Quasi-Transient A/C system model approach to the other two models is relatively simple within the CoolSim framework. This allows for a new system model to be developed with the Quasi-Transient version before the results are refined using the slower Fully Detailed version or accelerated using the faster Mapped-Component model version.
A CoolSim model of NREL's combined fluid loop (CFL) thermal management system was previously developed that included both active cooling and heating modes. Comparisons of simulated results with measured data validated the solution approach [9].

This paper focuses on the development of an energy saving control strategy concept for a HFO-1234yf CFL system using CoolSim. This control approach includes a mode selection algorithm and associated controllers for the compressor speed, cabin blower flow rate, and front-end heat-exchanger coolant bypass. This controlled CFL system model enabled a simulation comparison of the system's efficiency over different drive cycles. The drive-cycle-based thermal-system performance was then used to estimate the impacts on vehicle efficiency and range using NREL's FASTSim vehicle model.

To analyze additional energy benefits provided by motor preconditioning, simulations where the motor was preheated to $55^{\circ} \mathrm{C}$, the temperature set point for the heater air discharge temperature, were also performed.

\section{Approach}

\section{Model Description}

CoolSim's "Quasi-Transient" modeling method was employed for both refrigerant and coolant circuits in this study. The details of the solution method are discussed in []․ Both refrigerant and coolant circuits are represented by $0-\mathrm{D}$ volumes connected with $1-\mathrm{D}$ pipes, valves, or orifices. In general, any system component that can provide a flow rate due to a pressure differential can be attached to these 0-D volume blocks. For example, for the coolant loop network topology, these 0 -D volume blocks are used as junctions to connect lines for the purpose of the numerical solution. 0-D volume blocks can also be used to model physical components such as expansion tanks and heat exchanger headers in both coolant and refrigerant circuits.

The 1-D pipe block assumes a constant coolant mass flow rate along its length. The flow rate then becomes a simulation state variable. At each time step, the coolant pressure differential across each line is compared to pressure difference between the $0-\mathrm{D}$ junctions that they connect. A numerical method is applied to continuously adjust the coolant mass flow rate in each of the lines. The goal of this method is to match the pressure drop in the line to the pressure difference between the junctions that the line connects. Ideally, sub-iterations would be continued until convergence is reached at each time step of the solution to ensure a diminishing difference between the pressure drop in the line and the pressure difference between the connected junctions. This would result in a steady-state solution corresponding to the instantaneous values of boundary conditions at each simulation time step (hence the name, "Quasi-Transient"). To speed up the solution, however, only a single iteration is done in each time step. This was found to be an acceptably accurate approach when the computational time-step is relatively small compared to the systemlevel thermal response characteristic time. In this case, the solution converges fast enough to account for transients. 
To further speed up simulations by increasing the solution time step, the notion of artificial bulk modulus was introduced. This allows for changing the relationship between pressure and density and thus the system "stiffness." By setting the artificial bulk modules smaller than the true bulk modulus of liquids, the numerical stiffness in coolant and liquid portions of refrigerant networks can be reduced. This quasi-transient solution method results in lost accuracy for fast transients (on the order of seconds), such as pump cycling. For steady-state conditions, however, the conservation of mass and energy for each junction and each of the 1-D pipes in the model is ensured. A typical thermal management network is a slowly changing "quasi-steady" system, especially in cases with constant rotational speed electric pumps. In such cases, a true conservation of mass and energy will be closely approximated by this method. Details of the coolant loop modeling approach can be found in [9]. For this research, the CoolSim framework was expanded by adding a new HFO-1234yf refrigerant modeling capability. The cabin model was also updated by taking into account heat exchange in ducts.

The HFO-1234yf refrigerant modeling capability required a new set of MATLAB S-functions written in the C-language for the 1-D lines and $0-\mathrm{D}$ volumes, the fundamental blocks of CoolSim models. These functions were, however, developed in a way that allows for easier implementation of new refrigerant capabilities in the future. A system that is schematically identical to NREL's CFL test bench but which uses HFO-1234yf refrigerant instead of R134a was modeled. As expected, the HFO-1234yf refrigerant exhibited some performance disadvantages compared to R134a. The loss of system capacity was within $10 \%$, which was consistent with expectations, and helps to qualitatively verify the implementation.

The cabin model was updated to account for heat exchange in cabin ducts. Three ducted air passes were considered: from cowl to the blower, from the heater outlet to the cabin vents, and from the cabin outlet to the blower (recirculated portion). Heat exchange between the duct air and the duct wall was accounted for using an effectiveness-NTU (number of transfer units) method whereas resistances restricted energy exchange between the duct wall and either the cabin or ambient air. This approach improved verification of the model without needing to consider details such as heat paths inside the instrument panel or engine/motor compartment that would be prohibitively complicated within CoolSim. By adjusting the values of resistances and parameters of the NTU method, the updated cabin model was successfully validated using data. In this study, a generic version of the model was used.

\section{Combined Fluid Loop System}

To study control strategies and efficiency gains for warm-up conditions of a CFL system, the updated CoolSim tool was used to build three model versions of NREL's CFL electric-drive vehicle thermal management system that is illustrated in Figures 1 and $\underline{2}$.

CoolSim's solution methods were validated with R134a refrigerant data obtained using the test bench shown in Figure 2. Validation results for the coolant-to-air heat exchange rates are presented in Figure 3. A complete validation report can be found in Titov et al. [9]. In this study, a HFO-1234yf version of CoolSim was used to build the following three models:
- The Full-CFL model, that is shown in Figure 1. The Full-CFL system engages a vapor compression cycle based heat pump (HP) to pick up heat from a colder ambient air and deliver this heat to the cabin. It also includes a positive temperature coefficient (PTC) electrical resistance heater and a waste heat recovery sub-loop that recovers heat from the PE and EM. The EM is bypassed until its temperature exceeds the cooling inlet temperature.

- $\quad$ The PTC + PEEM system. This system concept maintains heat recovery from the PEEM but excludes the HP capability.

- The PTC-only system. This system uses a coolant PTC heater that provides cabin heating via a coolant network and a coolantto-air cabin heater. Losses on the lines are not included so that the system has only small efficiency disadvantages as compared to an air-PTC system

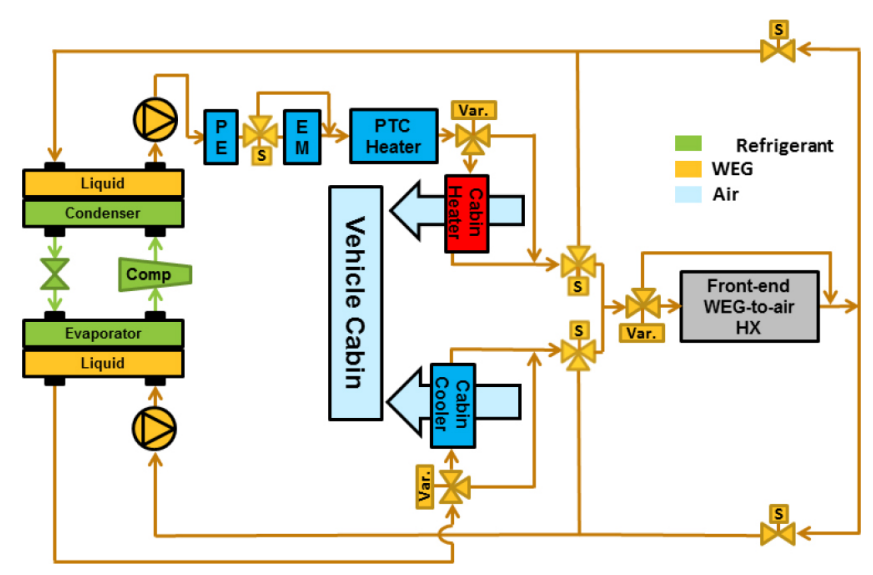

Figure 1. Schematic of NREL's CFL system. Battery is not shown.

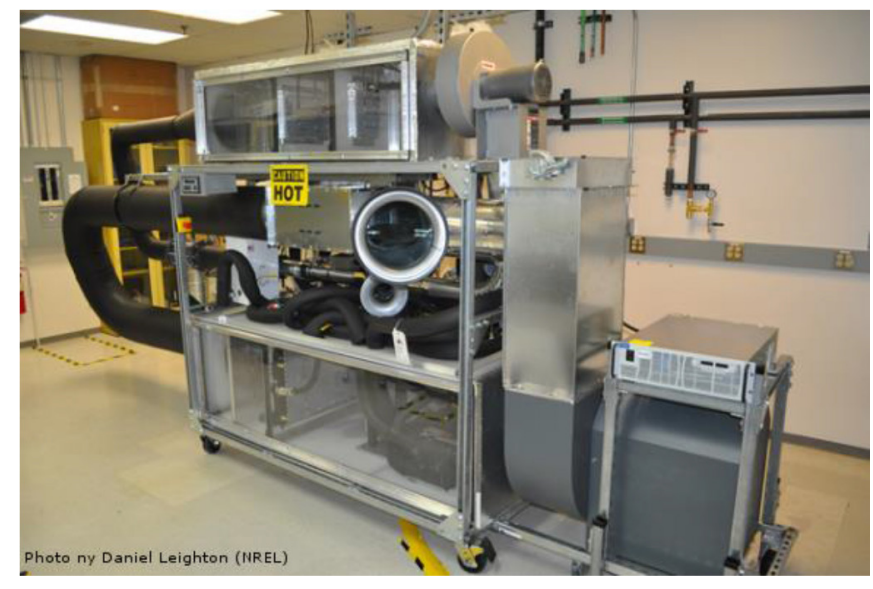

Figure 2. NREL's CFL test bench (Photo by Daniel Leighton, NREL)

For preheated cases, the PEEM initial temperature was $55^{\circ} \mathrm{C}$. This could be achieved using the PTC heating in the high-side coolant loop. Pre-conditioning the PEEM was selected because it is expected to have lower losses than the cabin during pre-conditioning. A separate study is planned to consider benefits of cabin preheating in more detail. 


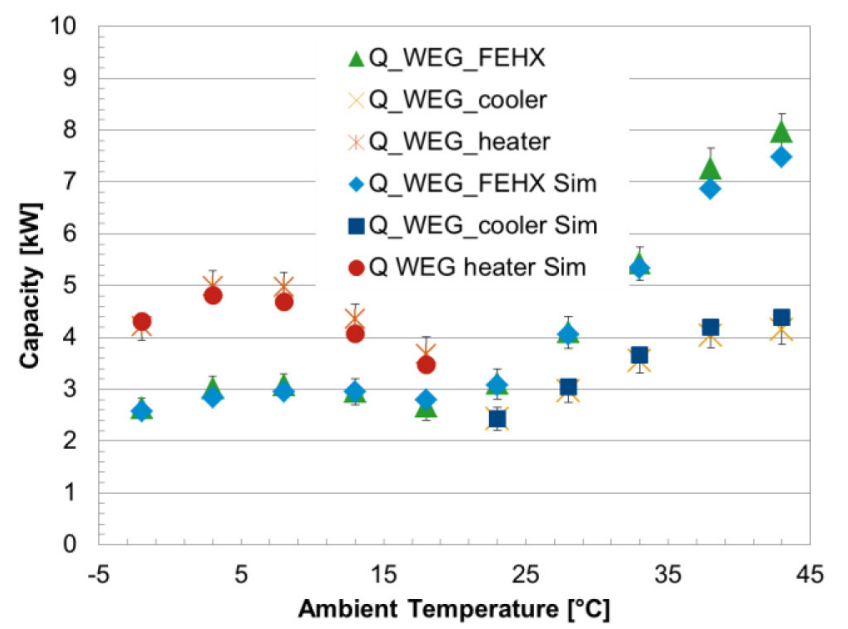

Figure 3. CoolSim validation results. Simulated and measured capacities of coolant-to-air heat exchangers $(\mathrm{HX}) . \mathrm{RMS}=4.18 \%$. Nine out of 10 points fall within $95 \%$ of uncertainty intervals. Error bars show $95 \%$ confidence intervals for measurement uncertainties. The maximum measurements uncertainty is $\pm 300 \mathrm{~W}$.

\section{The System Control Strategy}

Similar control algorithms were developed for each variant of the system. Two major control goals were pursued: a cabin air temperature set point of $22^{\circ} \mathrm{C}$, and the heater air-discharge temperature of $55^{\circ} \mathrm{C}$. The cabin air temperature was controlled by cabin blower mass flow rate, and the heater discharge temperature was controlled by compressor rotational speed, PTC power, and front-end heat-exchanger (FEHX) bypass on the coolant side depending on the mode and the model variant.

The Full-CFL system has multiple modes of operation. For the purposes of this study, the following three heating modes were considered as illustrated in Figure 4:

- Mode 1: PEEM heat recovery only-in this mode, there is sufficient waste heat from the PEEM to heat the cabin and no additional power is needed. If at any point the PEEM approaches its maximum inlet coolant temperature, then some coolant is routed through the FEHX to reject heat to the environment and keep the PEEM sufficiently cool.

- Mode 2: Heat pump with PEEM heat recovery-in this mode, the coolant accepts heat from the condenser (a coolant-to-refrigerant heat exchanger). The condenser heat is delivered by a vapor compression heat pump that pulls heat from the ambient using the front-end heat exchanger. The coolant then goes through the PEEM, accepting available waste heat. The compressor speed is controlled to regulate the cabin heater exit temperature to $55^{\circ} \mathrm{C}$. It is also ensured that the PEEM inlet temperature is below its design limit.

- $\quad$ Mode 3: Heat pump complemented by PTC heating and PEEM waste heat recovery-in this mode, the heat pump is operated at its full capacity as long as the coefficient of performance (COP) remains above 1 . Coolant exits the condenser and then picks up waste heat from PEEM. The PTC heater is then used to provide additional power to meet the cabin heater exit temperature set point. As long at the heat pump COP is above 1, this provides efficiency benefits over PTC heating.
In all three modes, the EM was bypassed by the cooling system for as long as its temperature remained below the coolant temperature at the inlet. This allowed for energy savings by not spending battery power on motor heating when its temperature was below the coolant temperature.

The control algorithm consisted of two layers, as shown in Figure 4. The first layer is a mode selection layer that chooses one of these three modes based on the system and environmental conditions. The second layer then provides component control, within the mode constraints, to maintain cabin and heater exit temperature set points. Initially, the first-layer control selects either Mode 3 or Mode 2 for a fast cabin warmup. Mode 3 provides the maximum heating power capability; but at warmer temperatures, it can cause a large overcapacity and thus overshoot the set point. To determine the initial warm-up mode, an independent study was performed that compared available PEEM waste heat to cabin thermal load for several drive cycles. At below $5^{\circ} \mathrm{C}$, Mode 3 was initially engaged, whereas at higher temperatures, Mode 2 was initially used.

The second-layer controls consisted of several PID controllers that maintained a preset cabin air temperature of $22^{\circ} \mathrm{C}$, the cabin heater air discharge temperature at $55^{\circ} \mathrm{C}$, and the PEEM coolant inlet temperature below $60^{\circ} \mathrm{C}$. These controllers included:

- Blower flow rate controller that adjusts the blower mass flow rate to attain and maintain the cabin air temperature set point of $22^{\circ} \mathrm{C}$.

- Compressor controller that adjusts compressor rotational speed in Mode 2 to maintain the preset heater air discharge temperature of $55^{\circ} \mathrm{C}$. (This controller is overridden in Mode 3, and the compressor is set at maximum as long as the COP is greater than 1).

- $\quad$ PTC power controller that adjusts complementary PTC power in Mode 3 when the compressor speed is at its maximum to maintain a heater discharge temperature of $55^{\circ} \mathrm{C}$.

- Front-end heat exchanger bypass controller that ensures that the PEEM inlet coolant temperature is below a preset limit of $60^{\circ} \mathrm{C}$ in Mode 1 in cases when PEEM waste heat was excessive for cabin heating.

- Coolant pump pulse width controller that maintains the coolant flow rate.

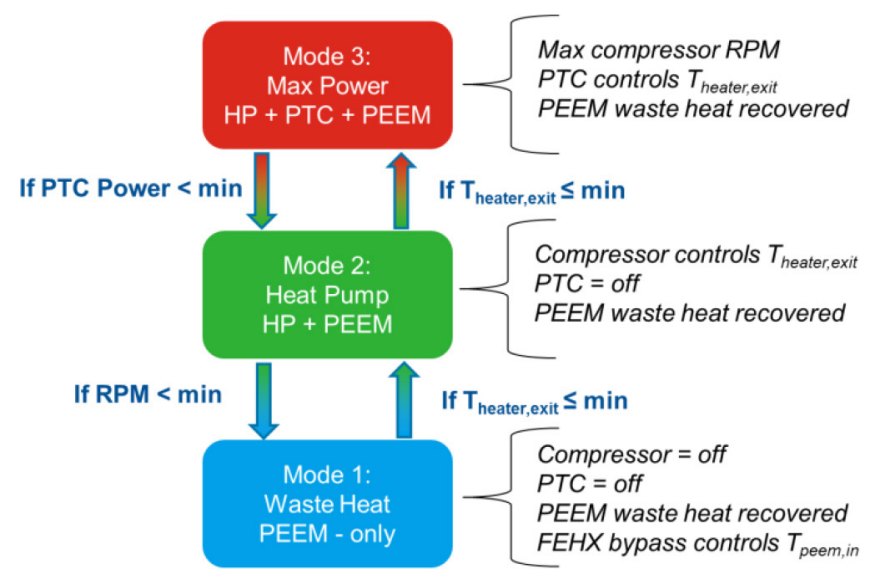

Figure 4. Two-layer control structure.

All of the temperature set points are presented in Table 1. 
Table 1. Temperature set points.

\begin{tabular}{|l|l|}
\hline Cabin temperature & $22^{\circ} \mathrm{C}$ \\
\hline Heater air discharge temperature & $55^{\circ} \mathrm{C}$ \\
\hline PEEM inlet coolant temperature limit & $60^{\circ} \mathrm{C}$ \\
\hline
\end{tabular}

At temperatures below or equal to $5^{\circ} \mathrm{C}$, Mode 3 is initially selected for maximum warm-up performance. In this mode, the system relies on the PTC power controller to maintain the heater air discharge temperature at $55^{\circ} \mathrm{C}$ while keeping the compressor at maximum speed if the COP remains above 1. Once the required PTC power decreases below its lower limit (10 watts), the first-layer controller switches to Mode 2, disengaging the PTC and switching to compressor speed control. When the compressor rotational speed decreases below the lower limit (500 rpm), the first-layer controller switches to Mode 1, turning off the vapor compression system and PTC heater, thus relying only on the PEEM waste heat. In Mode 1, the FEHX coolant bypass controller is engaged to prevent the PEEM from overheating by directing a part of the hot coolant to the FEHX so that excess heat can be dissipated to the ambient air. At ambient temperatures above $5^{\circ} \mathrm{C}$, Mode 2 is initially selected to prevent overcapacity and overshoot but otherwise the process is the similar.

The first-layer controls also handle the reverse mode switches going from Mode 1 to Mode 2 and from Mode 2 to Mode 3. If the system is in Mode 1 and the heater air discharge temperature falls below $50^{\circ} \mathrm{C}$, the system switches to Mode 2 (HP with PEEM heat recovery); if the system is in Mode 2 and heater air discharge temperature falls below $53^{\circ} \mathrm{C}$, the system switches to Mode 3 (HP power supplemented by PTC heating and waste heat recovery). The control algorithm also includes time delays and signal treatment to make sure instabilities and overshoots do not cause chaotic system behavior. For example, temperature measurements are taken over a period of time to make sure a control decision is not made based on a temperature spike. Controller resets were implemented on mode switch events so that the compressor, PTC, and FEHX bypass were engaged at reasonable initial conditions in accordance with the new mode of operation.

An attempt was made to make sure that the control algorithm relies only on measurable variables such as temperatures. However, the blower mass flow rate was adjusted directly to maintain the cabin air temperature (as opposed to controlling blower rotational speed) due to a lack of reliable blower performance curves. Still, all the control inputs used by the algorithms are either directly measurable on a vehicle or closely related to measureable parameters. The systems were evaluated over a range of ambient temperatures between $-20^{\circ} \mathrm{C}$ and $+20^{\circ} \mathrm{C}$. The constraints imposed on the systems are presented in Table 2 .

To test the control algorithm and to accurately estimate the CFL energy savings and range benefits, the three thermal management systems were evaluated over two transient drive cycles. Transient drive cycles are important for capturing the effects of the available PEEM waste heat and the cabin loads.
Table 2. System constraints.

\begin{tabular}{|l|l|}
\hline Maximum compressor rotational speed & $8,000 \mathrm{rpm}$ \\
\hline Minimum compressor rotational speed & $500 \mathrm{rpm}$ \\
\hline Maximum blower mass flow rate & $0.14 \mathrm{~kg} / \mathrm{s}(\sim 250 \mathrm{cfm})$ \\
\hline Maximum PTC power & $7 \mathrm{~kW}$ \\
\hline Minimum PTC power & $10 \mathrm{~W}$ \\
\hline Coolant flow rate & $0.23 \mathrm{~kg} / \mathrm{s}(\sim 10 \mathrm{~L} / \mathrm{min})$ \\
\hline Cabin air temperature set point & $22^{\circ} \mathrm{C}$ \\
\hline $\begin{array}{l}\text { Heater air discharge temperature set } \\
\text { point }\end{array}$ & $55^{\circ} \mathrm{C}$ \\
\hline Occupant heat generation rate & $140 \mathrm{~W}$ \\
\hline Air recirculation fraction & $85^{\circ}$ \\
\hline Ambient air relative humidity & $50^{\circ}$ \\
\hline $\begin{array}{l}\text { Initial electric motor initial temperature } \\
\text { in cases with motor preheating }\end{array}$ & $55^{\circ} \mathrm{C}$ \\
\hline
\end{tabular}

The average commute travel time in the United States is 22.85 minutes [10]. This is a relativity short time period for vehicle warmup and will heavily weight the transient effects over steady state.

Consistent with NREL's CFL bench testing paper [11], drive cycles were selected to match this time period and approximate a realistic mix of urban and highway driving. The UDDS is a city cycle and is 22.9 minutes long. The HWFET cycle represents highway driving, and by running two back-to-back cycles (HWFET2X), a total duration of 25.5 minutes is achieved. For the final combined impact estimation, these cycles will be weighted $45 \% / 55 \%$ UDDS and HWFET2X.

\section{Vehicle Model}

NREL's FASTSim program was used to determine the available waste heat and the impact of the system loads on the vehicle. In FASTSim, an example electric sedan model was used to predict PEEM waste heat available over the drive cycles. A 23-kWh battery and 107-kW motor were used. The peak PEEM efficiency was 93\%. The coefficient of drag, frontal area, and curb mass were $0.341,2.77 \mathrm{~m}^{2}$, and 1,622 $\mathrm{kg}$, respectively. The model provided a baseline energy use of 317 $\mathrm{kWh} /$ mile, which was close to the $320 \mathrm{kWh} /$ mile expected from published data. Further information on FASTSim vehicle models can be found in Brooker et al. [12]. The heat generation profile and vehicle velocity were then used in CoolSim during the warm-up simulations. This impacted both the waste heat available and cabin load. The total climate control system power required over time from CoolSim was then imposed as an auxiliary load in FASTSim, and the impact on vehicle energy use and range was simulated.

\section{Results and Discussion}

\section{HWFET2X Drive Cycle}

The HWFET2X drive cycle velocity (blue) and waste heat profile (red) are shown in Figure 5. These velocities affect the external cabin heat transfer, and thus impact the cabin heat demand. The heat generated from the PEEM operating over the drive cycles was first simulated by FASTSim and then was provided as an input for the simulation. 


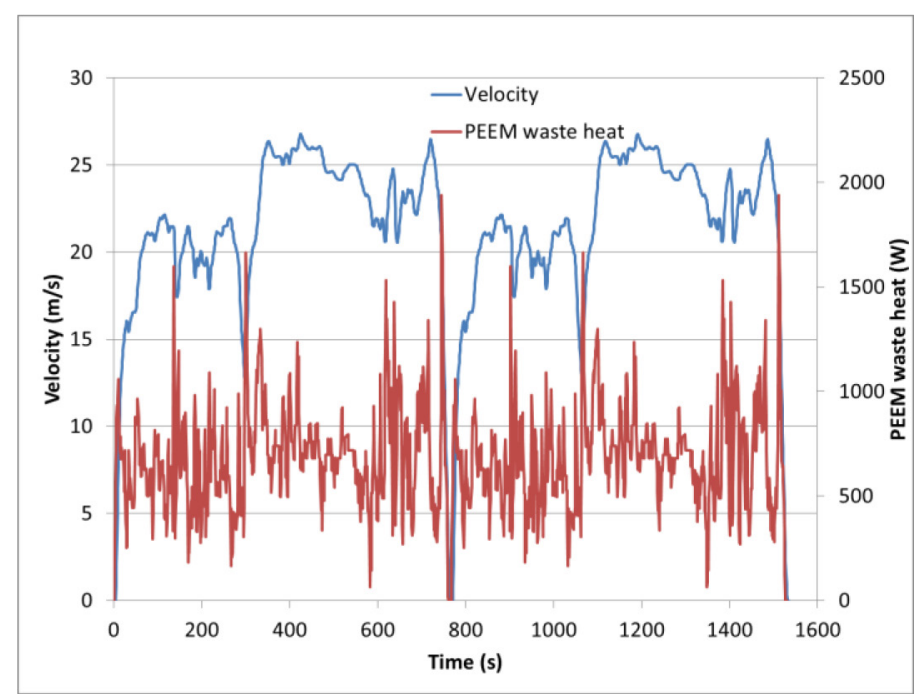

Figure 5. HWFET2X - Cycle velocity profile and PEEM waste heat.

Figure 6 shows the heat delivered to the cabin by the heating system. As shown in the figure, the power initially spikes as the vehicle starts from a cold soak. The controller tries to quickly warm up the cabin and then gradually decreases over the duration of the drive cycle as the vehicle warms. The heating system needs to match the demand, and its control algorithm has to deliver the needed heating capacity in the most efficient manner using various modes of operation.

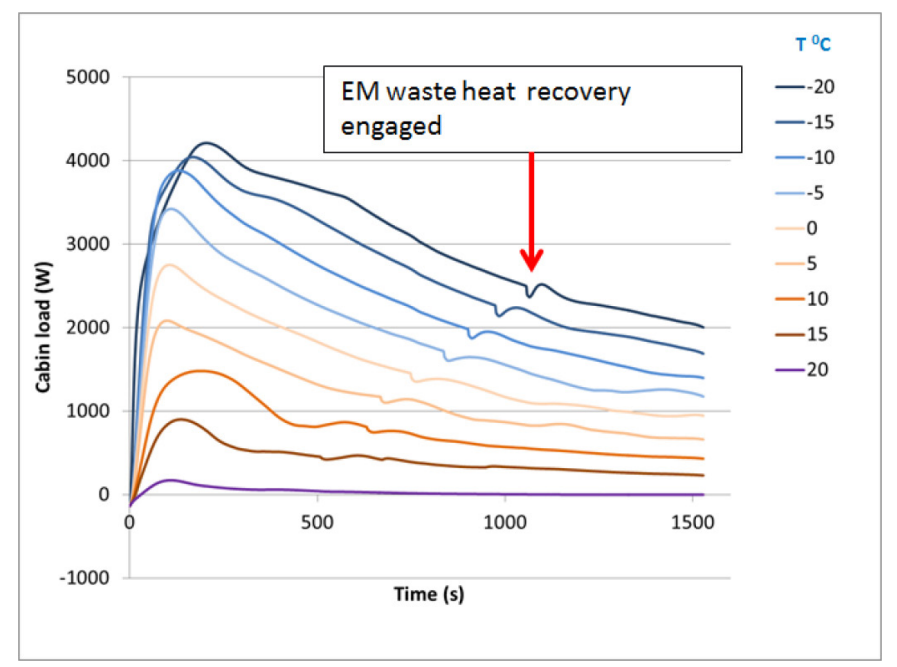

Figure 6. HWFET2X - Cycle cabin heat delivered by the full system.

An example of how the CFL system manages the cabin heating at an ambient temperature of $+5^{\circ} \mathrm{C}$ is shown in Figure 7 .

The mode number is shown in red (left vertical axis) and the difference between the cabin heating power needed and available PEEM waste heat is shown in blue (right axis). When the blue curve representing this difference reaches zero, the PEEM waste heat is sufficient to heat the cabin. The system starts in Mode 3 and quickly warms the cabin by engaging all of the available heating resources (HP, PTC, and PEEM). When the PTC power is no longer needed, the system switches to Mode 2 (HP and PEEM heat recovery). At 650 seconds into the cycle, the EM temperature reaches the inlet coolant temperature and it is added into the coolant loop. After this time waste heat from the EM is available. At around 840 seconds into the drive cycle, the difference between the needed heat and available
PEEM waste heat power falls below zero. This causes the compressor speed to fall below $500 \mathrm{rpm}$ and switches the system into Mode 1 (PEEM energy recovery only). The controller then senses a falling heater air discharge temperature due to increased cabin heating demand and briefly switches to Mode 2, turning the HP back on. When the demand decreases again, the compressor speed once again falls below $500 \mathrm{rpm}$ and the controller switches to Mode 1. From there, it keeps the system in Mode 1 for the rest of the drive cycle due to sufficient waste heat.

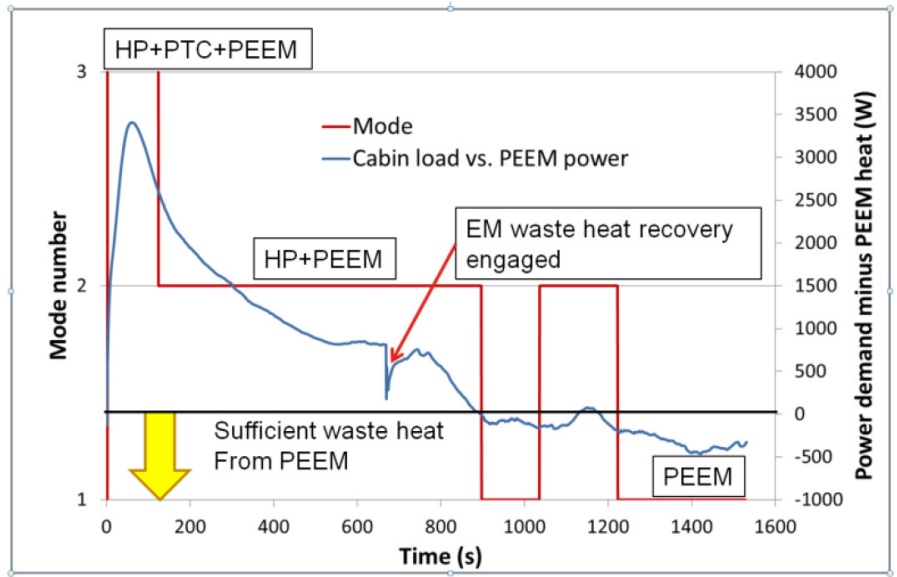

Figure 7. HWFET2X - Energy balance and mode selection at $+5^{\circ} \mathrm{C}$.

Figure 8 shows the energy difference between the cabin heating power delivered and heat exchange rate from the PEEM to the coolant for all of the cases considered. This is the supplemental heat needed in addition to waste heat. At temperatures below $-5^{\circ} \mathrm{C}$, the difference is always greater than zero, which indicates that the available PEEM energy is not sufficient for cabin heating at any point during the drive cycle. Starting at $0^{\circ} \mathrm{C}$, the additional heat needed falls below 0 on the graph, indicating there is sufficient waste heat. At higher temperatures, this occurs closer to the beginning of drive cycle. At $+20^{\circ} \mathrm{C}$, PEEM energy is sufficient for cabin heating shortly after the beginning of the drive cycle.

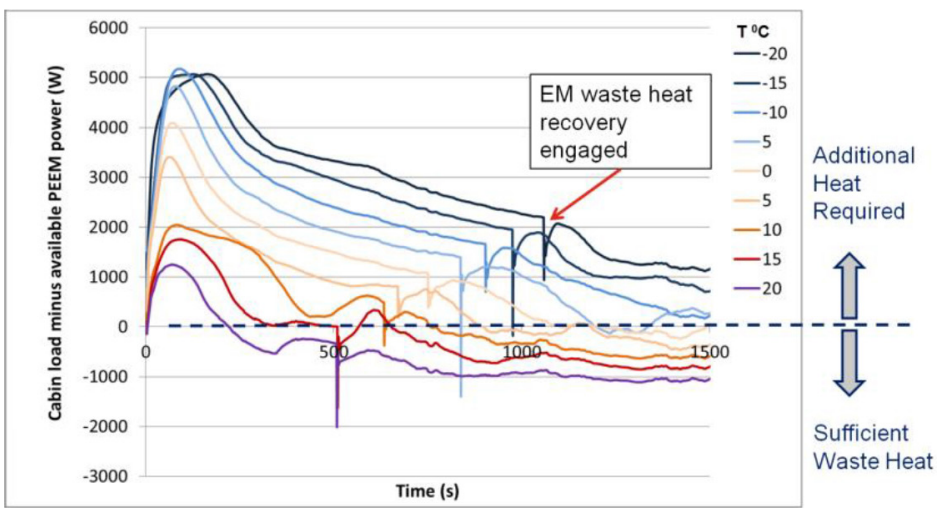

Figure 8. HWFET2X - Energy balance at all temperatures.

Figure 9 shows the PTC power. The PTC power complements other power sources when there is insufficient heating capacity to maintain the heater air discharge temperature at $55^{\circ} \mathrm{C}$. In cases of ambient temperature below $-10^{\circ} \mathrm{C}$, the $\mathrm{PTC}$ power initially stays at a maximum of $7 \mathrm{~kW}$ and then gradually decreases to zero. During this condition, the PTC is controlling the vent exit temperature. When the ambient temperature is above $5^{\circ} \mathrm{C}$, the PTC power is only engaged briefly to speed up the cabin warmup. 


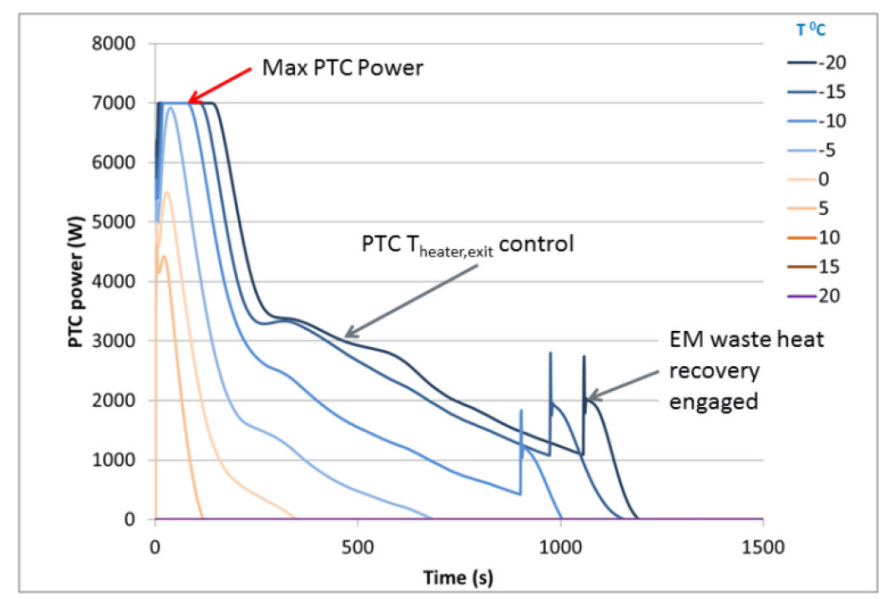

Figure 9. HWFET2X - PTC power.

In Mode 3, the compressor is held at maximum rotational speed while the PTC is used to control heater air discharge temperature. This condition can be seen at $-20^{\circ} \mathrm{C}$ in Figure 10 . When the system is in Mode 2, the compressor speed is controlled to maintain the heater air discharge temperature at $55^{\circ} \mathrm{C}$. At $-10^{\circ} \mathrm{C}$ the system can be seen switching into Mode 2 as the compressor rotational speed decreases from its maximum value.

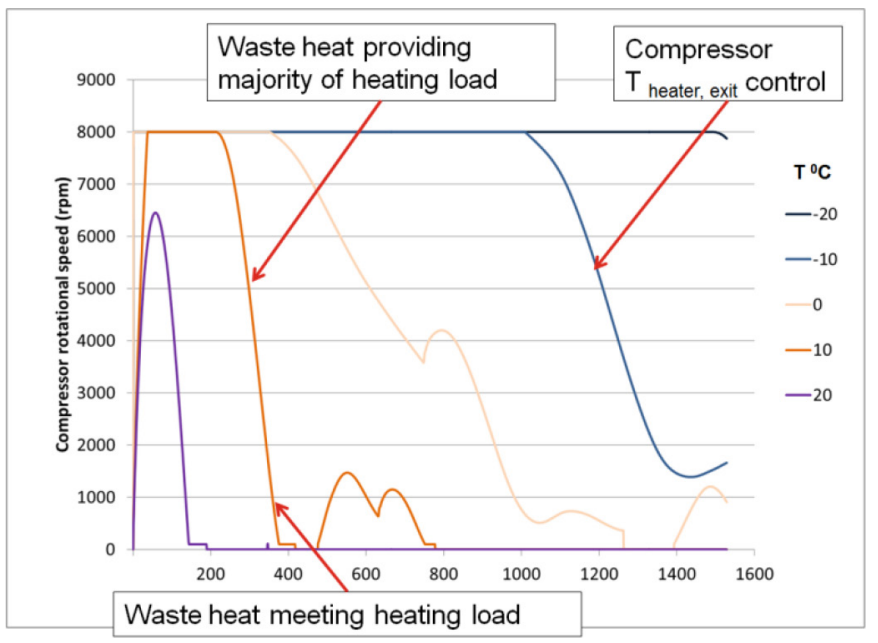

Figure 10. HWFET2X - Compressor rotational speed (rpm) control.

The compressor pressure, not shown, drops below the expected minimum value at $-20^{\circ} \mathrm{C}$. This was allowed in the simulation, but operation at this temperature may be more limited for some compressors.

The corresponding compressor power is shown in Figure 11.

It should be noted that the vapor compression cycle COP behavior was also monitored. Except for the initial 200 seconds, the COP never fell below 1, illustrating that the vapor compression system was used efficiently.

The blower flow rate, shown in Figure 12, is also initially engaged at full speed at low ambient temperatures to provide maximum heating to the cabin. Its flow rate is then controlled to maintain the cabin temperature at the set point of $22^{\circ} \mathrm{C}$.

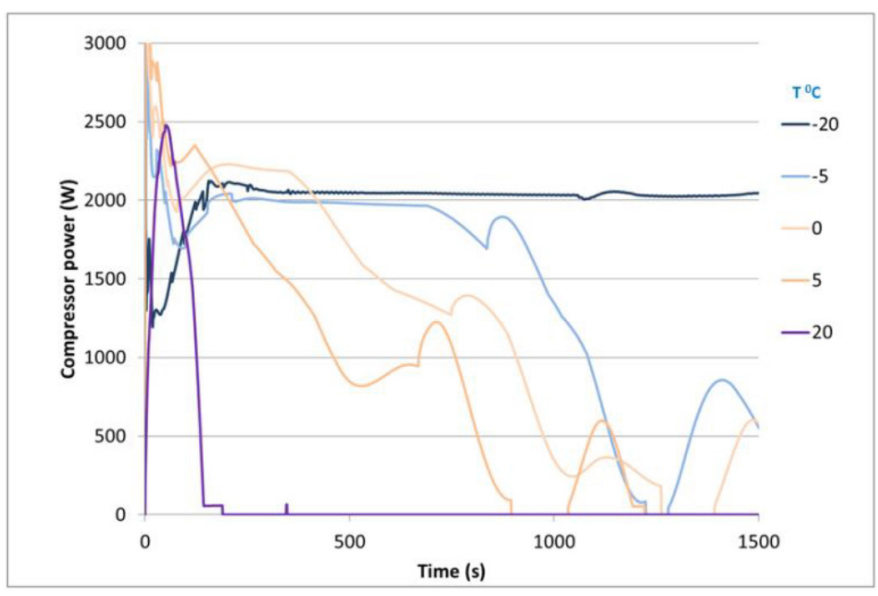

Figure 11. HWFET2X - Compressor power.

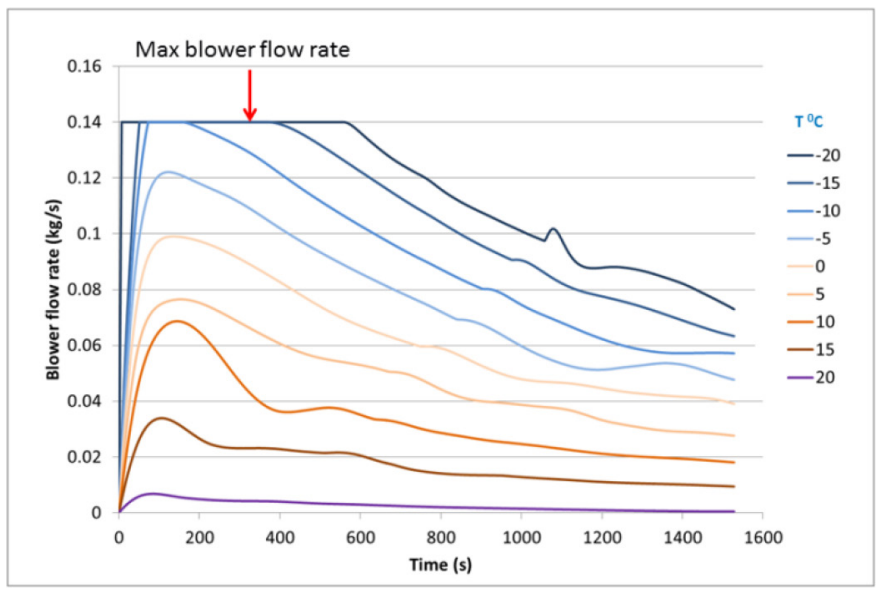

Figure 12. HWFET2X - Blower flow rate.

Figure 13 and Figure 14 show the response of cabin air temperature and heater air discharge temperature to control inputs for a range of ambient temperatures from $-20^{\circ} \mathrm{C}$ to $+20^{\circ} \mathrm{C}$.

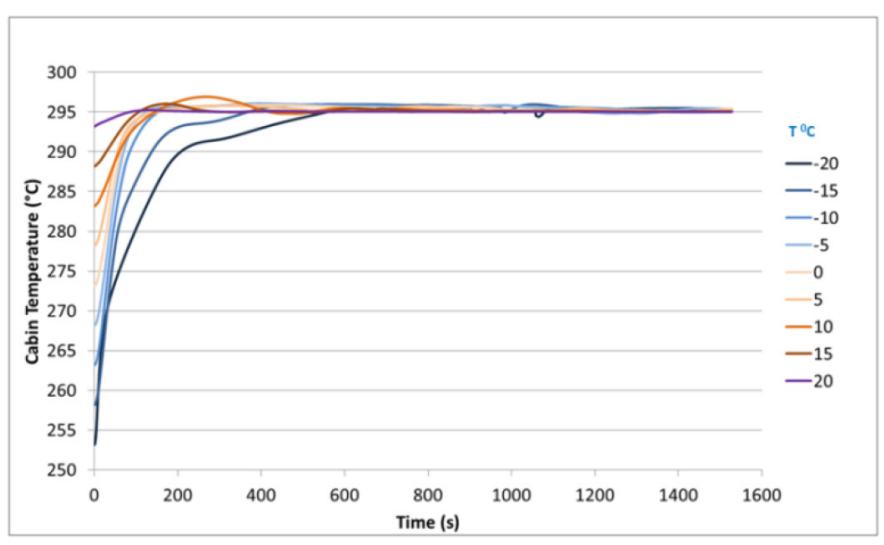

Figure 13. HWFET2X - Cabin air temperature.

As can be seen in Figure 13, the system attains and maintains a desired cabin air temperature of $+22^{\circ} \mathrm{C}$ at all ambient conditions; however, the time to reach the set point decreases with increasing ambient temperature. 


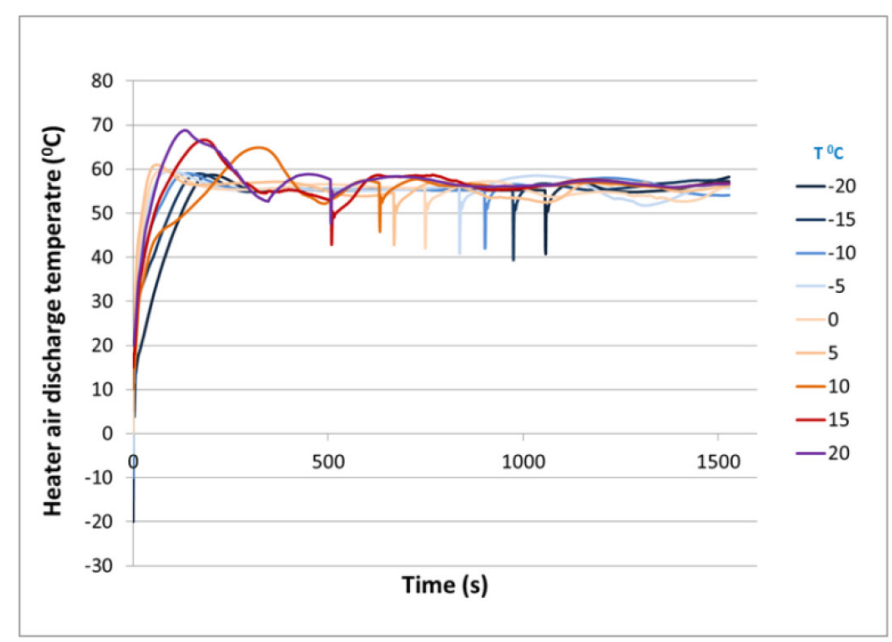

Figure 14. HWFET2X - Heater air discharge temperature.

The heater air discharge temperature overshoots the set point initially and then settles at the $55^{\circ} \mathrm{C}$ set point. The initial overshoot is on the order of $10^{\circ} \mathrm{C}$ and is a trade-off between a fast controller response causing the overshoot and longer times to the set point.

In addition to the Full-CFL simulations, Full-CFL with preheat, PTC+PEEM, and PTC cases were also modeled. Figure 15 and Figure 16 illustrate the level of energy savings achieved by the Full-CFL and PTC+PEEM system as compared to a PTC-only system. The figure also shows benefits of electric motor preheating to $55^{\circ} \mathrm{C}$, the set point of the heater air discharge temperature.

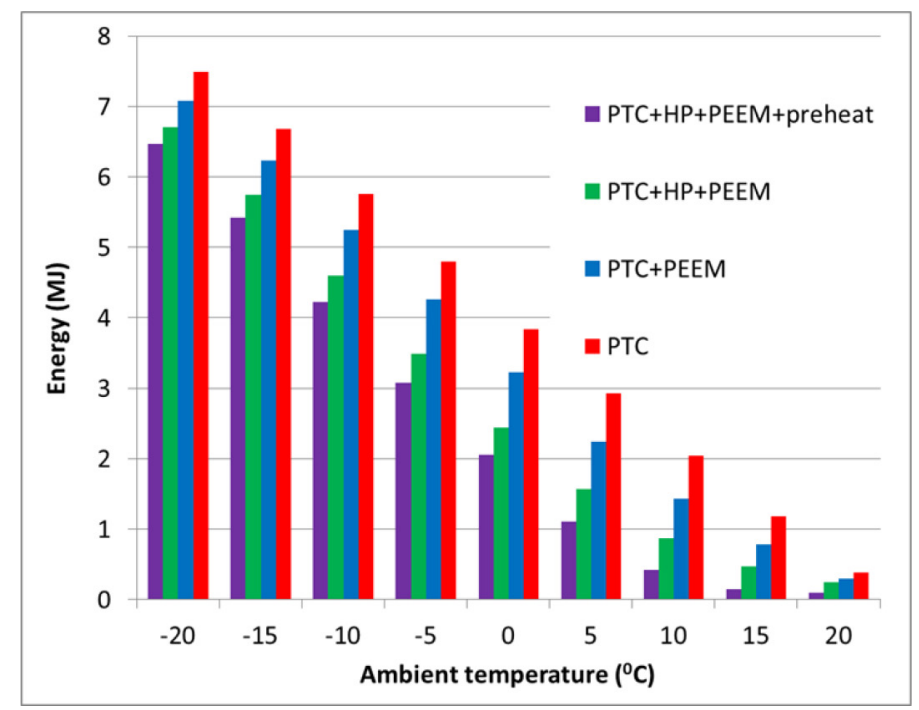

Figure 15. HWFET2X - Energy consumed by different system variants.

The Full-CFL and PTC+PEEM systems show considerable energy savings. The Full-CFL system has a maximum savings over the PTC system of more than $60 \%$ at an ambient temperature of $15^{\circ} \mathrm{C}$ and $80 \%$ when preheat is used.

The energy benefit increases with ambient temperature rise until it peaks at $15^{\circ} \mathrm{C}$. This effect is due to the lower efficiency of the vapor compression cycle at lower temperatures. At ambient temperatures close to the cabin set point, the efficiency decreases again due to the implemented control logic that brings the cabin temperature to the set point quickly by using more compressor power. This is, however, not a significant issue since the battery energy use at these ambient temperatures is minimal.

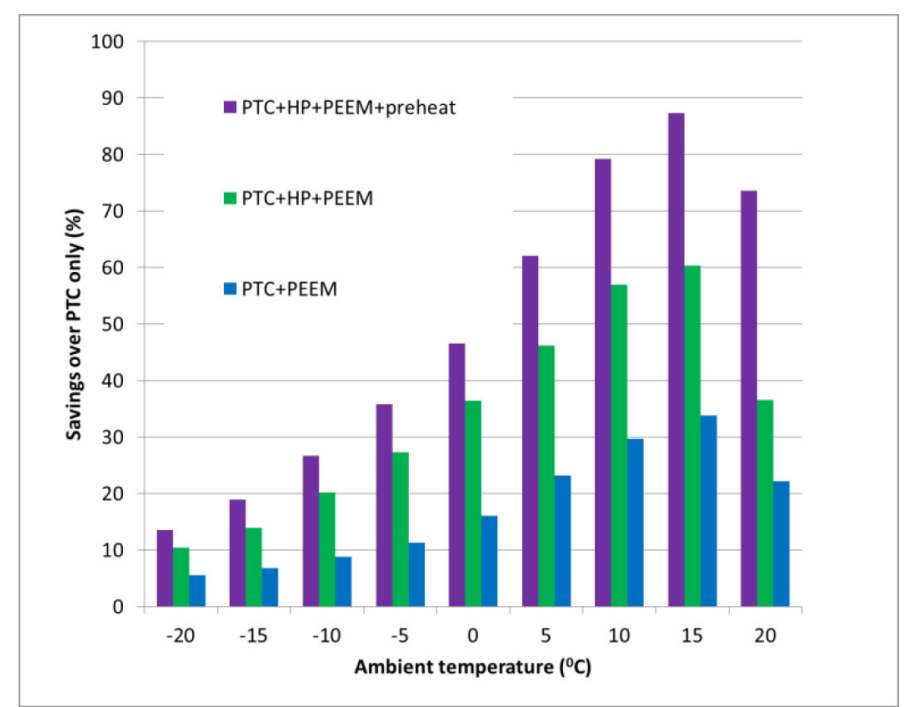

Figure 16. HWFET2X - Energy savings relative to PTC heating.

Savings of the PTC+PEEM system increase with ambient temperatures up to $15^{\circ} \mathrm{C}$, but are up to $20 \%$ lower than the full system with no preheating.

\section{UDDS Drive Cycle}

The UDDS drive-cycle vehicle speed and PEEM waste heat is shown in Figure 17. A similar study was performed for this drive cycle. Figure 18 shows the energy used for cabin heating for each of the system configurations, and Figure 19 shows percent savings. Similar to the HWFET2X cases, the Full-CFL system shows the maximum benefit. The effect of motor preheating is somewhat larger. The PTC+PEEM system does not show benefits at temperatures below $-5^{\circ} \mathrm{C}$ since the drive cycle does not provide enough time for the motor self-heating to the coolant temperature. The system becomes efficient at higher ambient temperatures, but remains significantly less efficient than the full system. The UDDS cycle provides less PEEM waste heat than the HWFET2X, reducing the heat recovery opportunity.

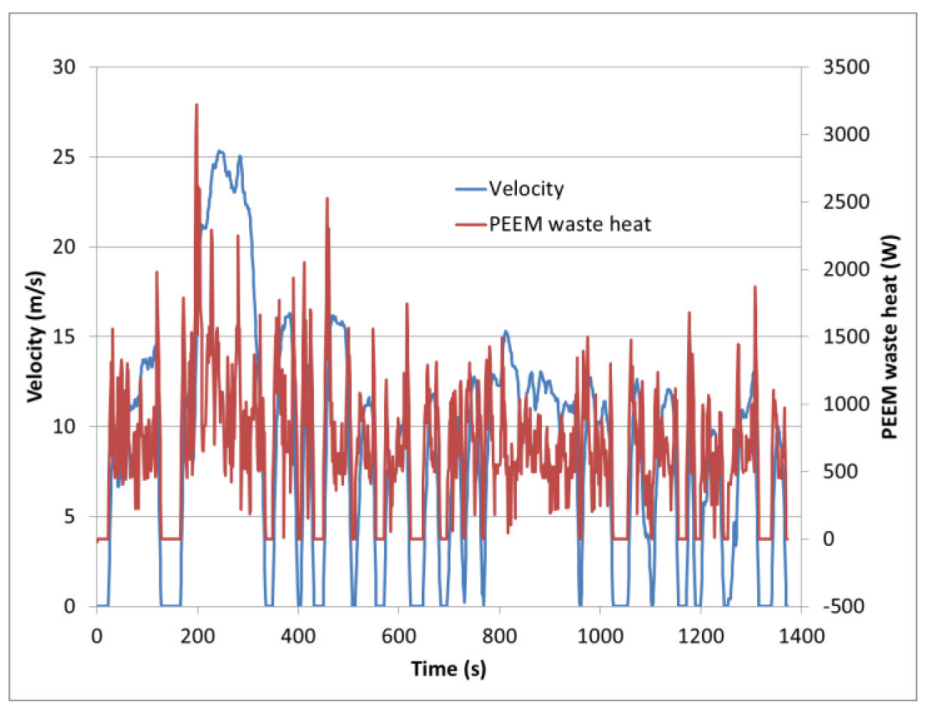

Figure 17. UDDS drive cycle vehicle velocity and PEEM waste heat. 


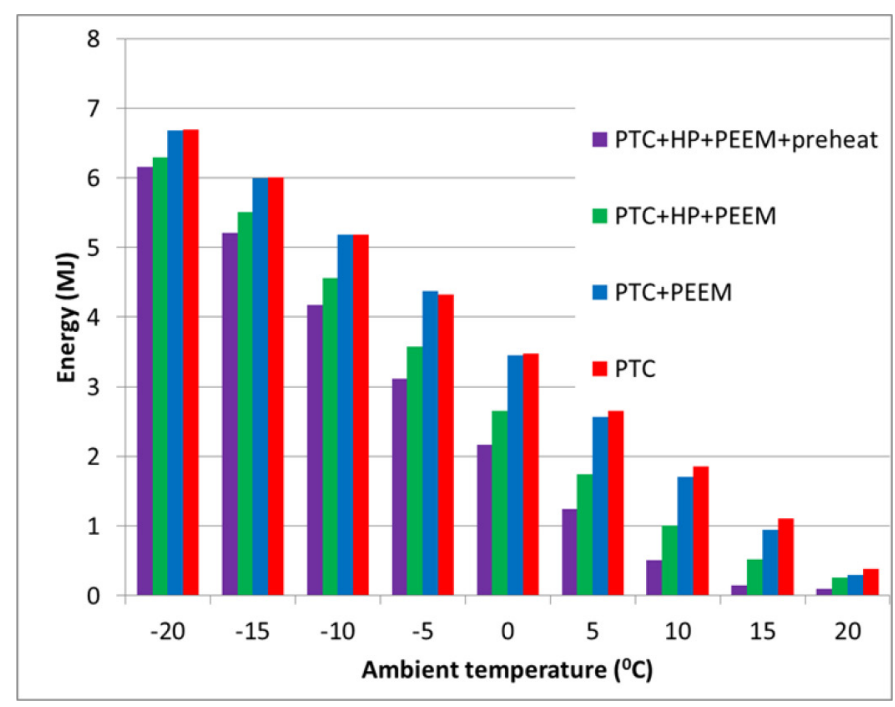

Figure 18. UDDS - Energy consumed by the system at various ambient temperatures.

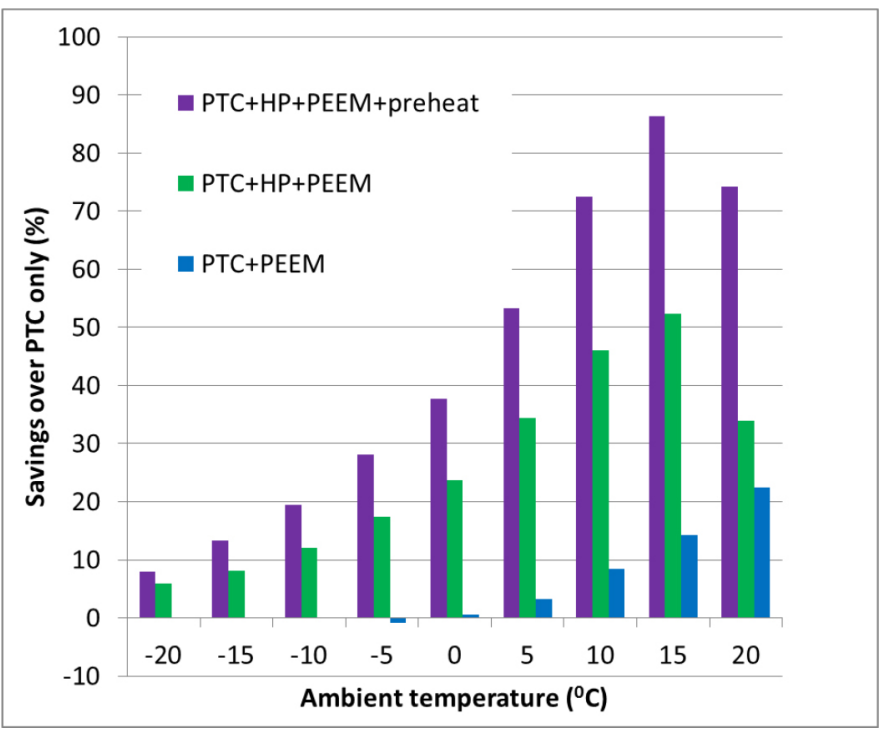

Figure 19. UDDS - Energy savings relative to PTC heating.

\section{Range Impact}

The thermal system electrical power demand for each drive cycle was calculated in CoolSim. This electrical demand was imposed on the vehicle model in FASTSim as a variable auxiliary load.

Due to the lower vehicle speed on the UDDS cycle, the cabin loads were lower. This more than offset the lower PEEM waste heat availability, resulting in smaller energy requirements. Due to the lower speed, however, the vehicle traveled less distance on the UDDS than the HWFET2X cycle-7.52 miles and 20.52 miles, respectively. Since the thermal loads are based on time and not on distance, this results in a larger thermal load per mile on the UDDS cycle, and thus, a larger impact on vehicle range. To illustrate a combined effect on the vehicle range, Figures 20 and 21 show weighted averages $(45 \%$ UDDS and 55\% HWFET2X) of the range and percent of range change. Figure 20 shows the range improvements provided by the Full-CFL and Full-CFL with preheat over the PTC-only system. As can be seen in the in Figure 21, a significant benefit is provided by the full system, with a maximum range improvement of $10.9 \%$ at $+5^{\circ} \mathrm{C}$ and $17 \%$ at $+10^{\circ} \mathrm{C}$ with preheat.

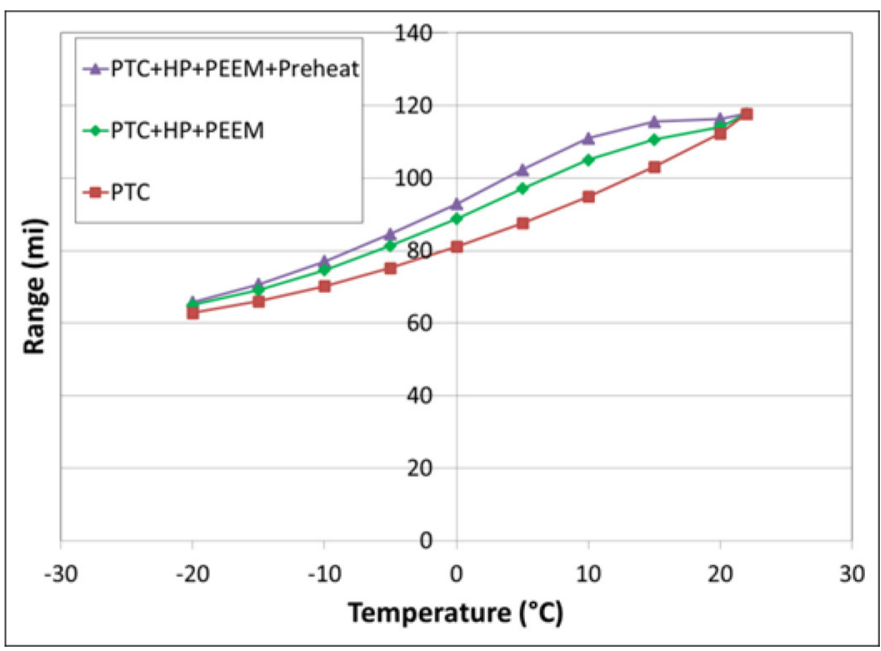

Figure 20. Weighted range $45 \%$ UDDS / 55\% HWFET2X.

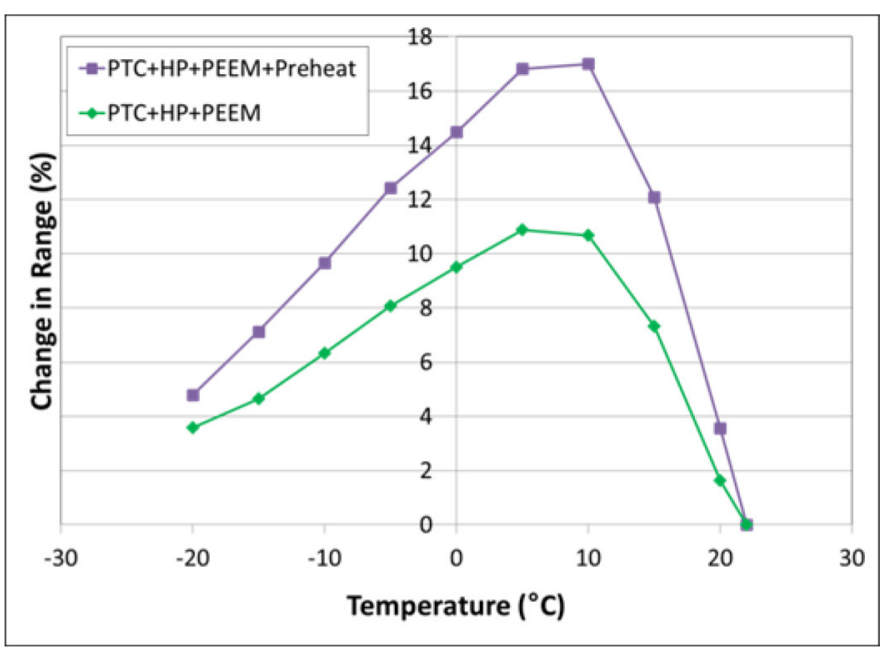

Figure 21. Weighted range impact 45\% UDDS 55\% HWFET2X.

\section{Summary/Conclusions}

NREL's MATLAB/Simulink thermal modeling framework CoolSim was improved and used to develop a control strategy for an advanced combined coolant loop system concept.

Improvements included a new HFO-1234yf refrigerant capability and an updated cabin model that accounts for heat exchange in ducts. The CFL system controls use a two-layer approach, with the first layer determining mode and the second layer controlling components within the mode constraints.

To determine the impact of the design on the vehicle loads and performance, simulations were done for two drive cycles. The HWFET2X and UDDS drive cycles were selected to represent a mix of typical highway and urban driving, and their duration was similar to the typical commute time in the United States. The controls successfully selected modes of operation and maintained the heater 
air discharge and cabin air temperatures close to set points in a stable manner over the drive cycles. Electric motor preheating saved additional battery energy. The CFL system showed significant energy savings in both drive cycles. The energy benefit changed with temperature and drive cycle, resulting in reductions from $12 \%$ to $80 \%$. Over the drive cycles, the weighted (45\% UDDS and 55\% HWFET2X) range improvement over the PTC-only system peaked at $17 \%$ with an ambient temperature of $+10^{\circ} \mathrm{C}$ and had notable benefits throughout the entire range.

The next steps will include adding traction battery thermal management to the simulations and more detailed power electronics and energy storage component models. A/C control modes will also be added. The heating and cooling loads will then be weighted by national temperature distributions to determine the national-level impact of the CFL system.

\section{References}

1. Rugh, J., Hovland, V. Andersen, S., 2004. Earth Technologies Forum and Mobile Air Conditioning Summit.

2. Francfort, J., and Murphy T.. 2007. "Operational and Fleet Testing, A. Hybrid Electric Vehicle Testing.” Chapter V. Advanced Vehicle Technology Analysis and Evaluation Activities: FY 2007 Annual Report. Washington, D.C.: Vehicle Technologies Program, U.S. Department of Energy; p. 145.

3. Umezu, K., and Noyama H.. 2010. “Air-Conditioning System for Electric Vehicles (i-MiEV).” SAE Automotive Refrigerant and System Efficiency Symposium.

4. Rask, E. 2014. “Advanced Technology Vehicle Lab Benchmarking - Level 2 (in-depth)" Presented at 2014 U.S. DOE Vehicle Technologies Program Annual Merit Review and Peer Evaluation Meeting.

5. “Autonomie." www.autonomie.org.

6. Brooker, A., Gonder, J., Wang, L., Wood, E. et al., "FASTSim: A Model to Estimate Vehicle Efficiency, Cost and Performance," SAE Technical Paper 2015-01-0973, 2015, doi:10.4271/201501-0973.

7. Kiss, T., Chaney, L., and Meyer, J., "A New Automotive Air Conditioning System Simulation Tool Developed in MATLAB/ Simulink," SAE Int. J. Passeng. Cars - Mech. Syst. 6(2):826840, 2013, doi:10.4271/2013-01-0850.

8. Kiss, T. and Lustbader, J., "Comparison of the Accuracy and Speed of Transient Mobile A/C System Simulation Models," SAE Int. J. Passeng. Cars - Mech. Syst. 7(2):739-754, 2014, doi:10.4271/2014-01-0669.

9. Titov, G., Lustbader, J., Leighton, D., and Kiss, T., "MATLAB/ Simulink Framework for Modeling Complex Coolant Flow Configurations of Advanced Automotive Thermal Management Systems," SAE Technical Paper 2016-01-0230, 2016, doi: $10.4271 / 2016-01-0230$.
10. Leighton, D., and Rugh J., 2014. "Electric Drive Vehicle Range Improvement Using a Combined Fluid Loop Thermal Management Strategy." Presented at the SAE Thermal Management Systems Symposium, Sept. 22-24, 2014, Denver, CO.

11. Santos, A.T., McGuckin N., Nakamoto H.Y., Gray D., et al. 2011. Summary of Travel Trends: 2009 National Household Travel Survey. Report \# FHWA-PL-11-022, U.S. Department of Transportation.

12. Brooker, A., Gonder, J., Wang, L., Wood, E. et al., "FASTSim: A Model to Estimate Vehicle Efficiency, Cost and Performance," SAE Technical Paper 2015-01-0973, 2015, doi:10.4271/201501-0973.

\section{Contact Information}

Gene V. Titov and Jason A. Lustbader

National Renewable Energy Laboratory

15013 Denver West Parkway

Golden, CO 80401

Phone: (303) 275-4443

Jason.Lustbader@nrel.gov

Gene.titov@nrel.gov

\section{Acknowledgments}

This work was supported by the U.S. Department of Energy under Contract No. DE-AC36-08GO28308 with the National Renewable Energy Laboratory. Funding was provided by the U.S. DOE Office of Energy Efficiency and Renewable Energy Vehicle Technologies Office and administered by David Anderson and Lee Slezak, DOE Program Managers. The U.S. Government retains and the publisher, by accepting the article for publication, acknowledges that the U.S. Government retains a nonexclusive, paid-up, irrevocable, worldwide license to publish or reproduce the published form of this work, or allow others to do so, for U.S. Government purposes.

Special thanks to industry partner MAHLE. Additional thanks to John Rugh and Lisa Fedorka (NREL).

\section{Definitions/Abbreviations}

A/C - air conditioning

CFL - combined fluid loop

COP - coefficient of performance

EM - electric machine

EV - electric vehicle

FASTSim - Future Automotive Systems Technology Simulator

FEHX - front end heat exchanger

HP - heat pump

HWFET2X - Highway Fuel Economy Test (two back-to-back 
cycles)

NREL - National Renewable Energy Laboratory

PE - power electronics

PEEM - power electronics and electric motor

PID - proportional-integral-derivative

PTC - positive temperature coefficient

UDDS - Urban Dynamometer Driving Schedule

WEG - water-ethylene glycol

The Engineering Meetings Board has approved this paper for publication. It has successfully completed SAE's peer review process under the supervision of the session organizer. The proces requires a minimum of three (3) reviews by industry experts.

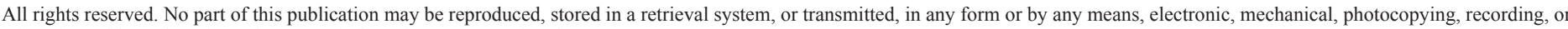
otherwise, without the prior written permission of SAE International.

Positions and opinions advanced in this paper are those of the author(s) and not necessarily those of SAE International. The author is solely responsible for the content of the paper.

ISSN 0148-7191

http://papers.sae.org/2017-01-0191 